\title{
Optimal Coordination of Overcurrent and Distance Relays Using Cuckoo Optimization Algorithm
}

\author{
Farhad Namdari*, Sajad Samadinasab, Nader Shojaei, Mohammad Bakhshipour \\ Departement of Electrical Engineering, Engineering Faculty, Lorestan University, \\ Daneshgah Street, 71234-98653, Khorramabad, Lorestan, Iran \\ *Corresponding author, e-mail: namdari.f@lu.ac.ir
}

\begin{abstract}
The duty of protective systems is the timely detection of fault and removing it from the power network. The accuracy of the results and reducing the execution time of the optimizing algorithm are two crucial elements in selecting optimizing algorithms in protective functions. The most important protective elements that are used in power networks are distance and overcurrent relays. In this article, a new algorithm is presented to solve the optimization problem of coordination of overcurrent and distance relays by using Cuckoo Optimization Algorithm which considers the non-linear model overcurrent relays at all stages of setting. The proposed method is tested on a standard 8-bus power system network. Also the results obtained have been compared with other evolutionary algorithms. The results show that the proposed approach can be provide more effective and practical solutions to minimize the time function of the relays and achieving optimal coordination in comparison with previous studies on optimal coordination of overcurrent and distance relays in power system networks.
\end{abstract}

Keywords: Cuckoo Optimization Algorithm, Optimization methods, Overcurrent relay, Distance relay, optimal coordination of relays, Power system protection.

Copyright $\odot 2015$ Institute of Advanced Engineering and Science. All rights reserved.

\section{Introduction}

One of the mainly common protective relays used in power systems from various faults is the overcurrent relay. Overcurrent relay (OCR) is a type of protective relay which operates when the load current exceeds a preset value [1,2]. Overcurrent relays are used as both primary and backup protection for heavily meshed and multi-source power network. Low cost and simplicity to implement are the merits of overcurrent relay application for Power system protection [3]. The issue of coordination of overcurrent relays includes time setting multipliers (TSM) and plug setting (PS) with applying related constraints on operating time difference between backup and primary relays [4]. Over the past five Decades, several studies have been carried out on optimal coordination of overcurrent relays. These studies can be divided into three categories: 1) Trial and error method 2) Structural analysis method 3) Optimization method [5-8]. In recent years, artificial intelligence methods and nature-inspired algorithms such as Evolution Programming [9], Genetic Algorithm (GA) [10-12], Particle Swarm Algorithm (PSO) $[13,14]$ among others are used to solve the issue of optimal coordination of overcurrent relays. The pickup value of an overcurrent relay must be set between the maximum load current and the minimum fault current experienced by the relay. In high voltage and extra-high voltage networks, these parameters are often not well defined, for a safe selection of a pickup setting. For such cases, the distance relay furnishes excellent protection under all circumstances. Therefore, in transmission and subtransmission systems, the coordination of $\mathrm{O} / \mathrm{C}$ and distance relays should be considered [15-18].

Today's power systems are very complex, large and interconnected. Because of the increasing dependence on electricity, ensuring its delivery in a secure and reliable manner is very importance to both customers and suppliers. On the other hand, short circuit conditions can occur unexpectedly in any part of a power system. The incidence of the fault is harmful and must be isolated by a set of protective devices. These lead to the need for a large number of protective relays cooperating with one another to assure the secure and reliable operation of a whole [19]. Relay Coordination in a meshed power network in highly tedious and time consuming affair. If any relay fails to respond the fault it is backed by another relay. The 
operation of primary relay is quick and back up relay operates after a certain time margin [20]. In fact relay coordination problem is to determine the sequence of relay operations for each possible fault location so that the faulted section is isolated with sufficient margins and without excessive time delays [21]. This study is a novel approach based on Cuckoo Optimization Algorithm (COA) which is presented to solve the optimal coordination of overcurrent and distance relays to improve the accuracy of the results and reducing the execution time of the optimizing algorithm. When the network is protected with distance relays, each line is protected by the main and backup relay of its line. By placing overcurrent relays along with distance relays, protective territory of the transmission network will expand. If a disturbance occurred, initially main distance relay will operates and if it fails to clear fault, overcurrent relay will operates. If main relay fails to operate, the backup distance relay will operate and if it fails to operate ultimately backup overcurrent relay must isolate the faulted section [22].

This article proposes an intelligent $\mathrm{O} / \mathrm{C}-\mathrm{O} / \mathrm{C}$ and $\mathrm{O} / \mathrm{C}$-distance relays coordination method based on Cuckoo Optimization Algorithm (COA). The distance relay is considered as the main relay and the overcurrent relay $(\mathrm{O} / \mathrm{C})$ is as the backup relay. In this method, from multiple zones of protection are used to cover the entire line dependably and securely. Also, from 50 to $200 \%$ in steps of $25 \%$, the current setting multipliers (PS) is changed to make the investigation more practical COA which has the advantages of three well known algorithms DE, GA and PSO. Sharing information between solutions is one of the GA's features [23]. In PSO, from each iteration to the next, solutions are saved but each saved solution is capable to learn from its neighbors and simultaneously with the progression of the algorithm, adapt itself [24]. Therefore, containing these features simultaneously, causes the superior performance of COA algorithm. This novel evolutionary algorithm, is suitable for continuous nonlinear optimization problems. Application of the proposed algorithm to some benchmark functions and a real problem has proven its capability to deal with difficult optimization problems. The key features of $\mathrm{COA}$ are the faster convergence rate and reduce computational complexity [25]. Results show which the proposed method has significantly reduced the execution time of the algorithm while improving the accuracy of the output results in comparison with the other nature-inspired algorithms such as PSO and GA those previously have been applied to the problem which demonstrate the ability of COA to solve non-linear optimization problems. All the simulations are carried out in MATLAB software. The rest of the paper is organized as follows: sections 2 explains problem formulation setting overcurrent and distance relays, respectively. Section 3 explains cuckoo optimization algorithm (COA). Section 4 represents use of the Cuckoo Optimization Algorithm (COA) for optimal coordination of overcurrent and distance relays. The simulation results are illustrated and discussed in section 5 and finally concluding remarks are drawn in section 6 .

\section{Problem Formulation}

\subsection{Setting overcurrent relays}

The objective function and constraints of the problem, to obtain the parameters of TMS and $I_{\text {set }}$ is defined as follows [26]:

$$
\begin{aligned}
& \text { Minimize: } \quad \sum_{i=1}^{n} t_{\text {opi }} \\
& \mathrm{t}_{\text {opi }}=f\left(T M S_{i}, I_{\text {Set }}\right)=\frac{3 T M S_{i}}{\log \frac{I_{\text {Sci }}}{I_{\text {Seti }}}}
\end{aligned}
$$
follows:

Where $\mathrm{n}$ is the number of overcurrent relays. Constraint optimization problem as

$$
\begin{aligned}
& T M S_{\operatorname{min~} \mathrm{i}} \leq T M S_{i} \leq T M S_{\operatorname{max~i}} \\
& t_{O p_{b}}\left(z_{m}\right)-t_{O p_{m}}\left(z_{m}\right) \geq C T I \\
& I_{\text {ioad }_{i}}^{\text {Max }_{i}}<I_{\text {set }_{i}}<I_{\text {fault }_{i}}^{\text {Min }}
\end{aligned}
$$


Where $t_{O p_{i}}$ is operating time $i^{\text {th }}$ relay, and $t_{O p_{b}}$ are operating time of primary and backup relays respectively and $\mathrm{CTI}$ is the Coordination Time Interval.

Constraint (3) is used for each pair main and backup relay $(m, b)$ and for errors relating to zone of protection $Z_{m}$. With respect to the Figure 1, the failures are identified by the $F 1$ and F2 points. Taking into account Constraint (4), the pickup value of an overcurrent relay must be set between the maximum load current and the minimum fault current experienced by the relay.

\subsection{Coordination by taking the distance relays}

When the network is protected with distance relays, each line is protected by the main and backup relay of its line. By placing overcurrent relays along with distance relays, protective territory of the transmission network will expand. If a disturbance occurred, initially main distance relay will operates and if it fails to clear fault, overcurrent relay will operates. If main relay fails to operate, the backup distance relay will operate and if it fails to operate ultimately backup overcurrent relay must isolate the faulted section. As shown in Figure 2 in order to establish the mentioned sequence protection, two other constraint should be added to the constraints of coordination problems:

$$
\begin{aligned}
& t_{b}(F 3)-t_{z 2} \geq C I^{\prime} \\
& t_{z 2}-t_{m}(F 4) \geq C I^{\prime}
\end{aligned}
$$

In (5) and (6) $t_{m}$ is operating time of overcurrent relay and $t_{z 2}$ is operating time of the second zone of distance relay. In this condition, a new coordination time interval ( $C I^{\prime}$ ) between distance and overcurrent relays should be defined, which does not have the same value as $C I$ that is used in coordination of overcurrent relays pairs.

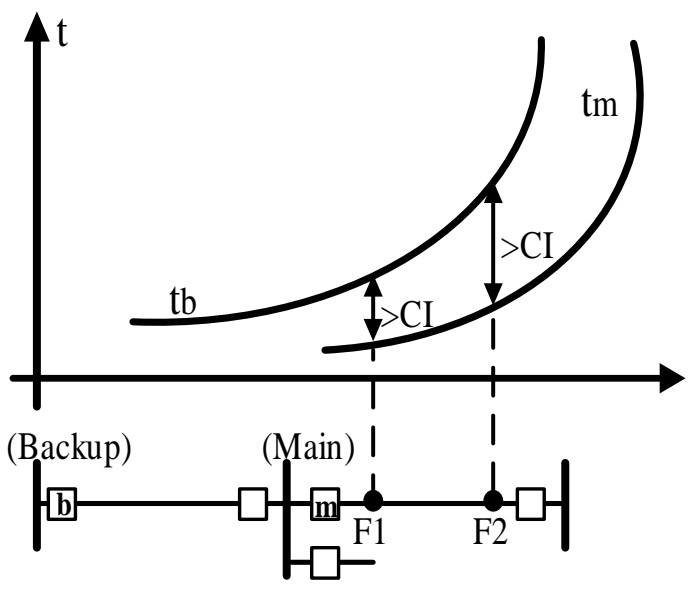

Figure 1. Coordination of overcurrent relays

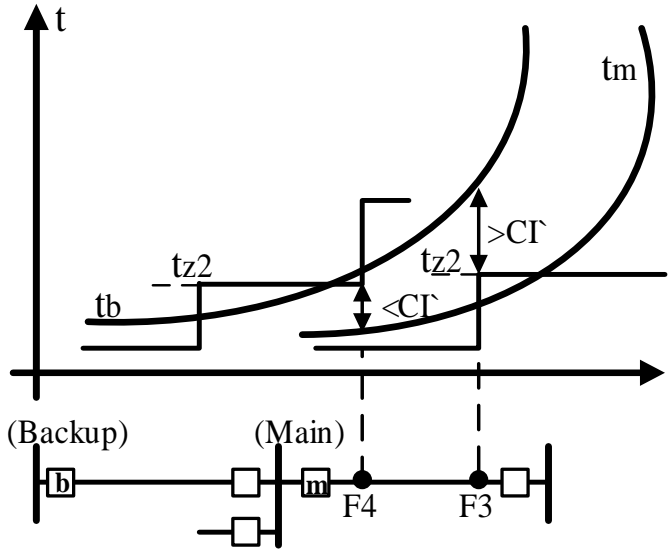

Figure 2. Coordination between distance and overcurrent relays

\section{The proposed Cuckoo Optimization Algorithm (COA)}

This optimization algorithm is inspired by the life of a bird family, called Cuckoo. Special lifestyle of these birds and their characteristics in egg laying and breeding has been the basic motivation for development of this new evolutionary optimization algorithm. This novel evolutionary algorithm, is suitable for continuous nonlinear optimization problems. The effort to survive among cuckoos constitutes the basis of Cuckoo Optimization Algorithm. During the survival competition some of the cuckoos or their eggs, demise. The survived cuckoo societies immigrate to a better environment and start reproducing and laying eggs. Cuckoos' survival effort hopefully converges to a state that there is only one cuckoo society, all with the same 
profit values. Application of the proposed algorithm to some benchmark functions and a real problem has proven its capability to deal with difficult optimization problems [25].

Figure 3 shows a flowchart of the proposed algorithm. Similar to other evolutionary methods, Cuckoo Optimization Algorithm (COA) starts with an initial population. These initial cuckoos have some eggs to lay in some host birds' nests. Some of these eggs which are more similar to the host bird's eggs have the opportunity to grow up and become a mature cuckoo. Other eggs are detected by host birds and are killed. The grown eggs reveal the suitability of the nests in that area. The more eggs survive in an area, the more profit is gained in that area. So the position in which more eggs survive will be the term that COA is going to point optimize.

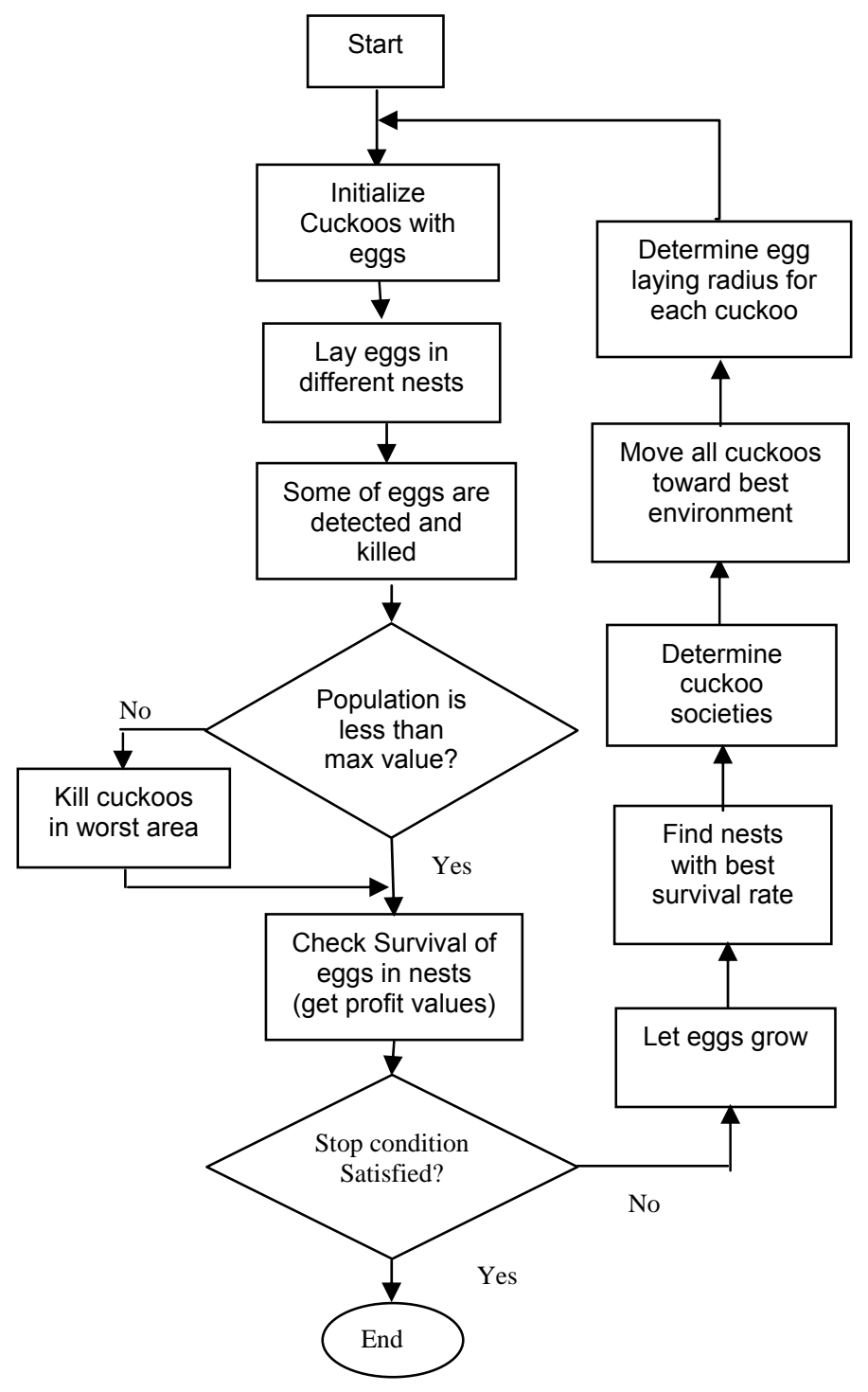

Figure 3. Flowchart of Cuckoo Optimization Algorithm

\subsection{Generating initial cuckoo habitat}

In order to solve an optimization problem, it's necessary that the values of problem variables be formed as an array. In GA and PSO terminologies this array is called "Chromosome" and "Particle Position", respectively. But here in Cuckoo Optimization Algorithm (COA) it is called "habitat". In a $N_{\text {var }}$ dimensional optimization problem, a habitat is an array of $1 \times N_{\mathrm{var}}$, representing current living position of cuckoo. This array is defined as follows: 
Habital $=\left[x_{1}, x_{2}, \ldots, x_{N \text { var }}\right]$

Each of the variable values $\left(x_{1}, x_{2}, \ldots, x_{N \text { var }}\right)$ is floating point number. The profit of a habitat is obtained by evaluation of profit function $f_{p}$ at a habitat of $\left(x_{1}, x_{2}, \ldots, x_{N \text { var }}\right)$. So

$$
\text { profit }=f_{p}(\text { habital })=f_{p}\left(x_{1}, x_{2}, \ldots, x_{N} \text { var }\right)
$$

As it is seen COA is an algorithm that maximizes a profit function. To use COA in cost minimization problems, one can easily maximize the following profit function:

$$
\text { profit }=-\operatorname{Cost}(\text { habital })=-f_{C}\left(x_{1}, x_{2}, \ldots, x_{N \text { var }}\right)
$$

To start the optimization algorithm, a candidate habitat matrix of size $N_{p o p} \times N_{\mathrm{var}}$ is generated. Then some randomly produced number of eggs is supposed for each of these initial cuckoo habitats. In nature, each cuckoo lays from 5 to 20 eggs. These values are used as the upper and lower limits of egg dedication to each cuckoo at different iterations. Another habit of real cuckoos is that they lay eggs within a maximum distance from their habitat. From now on, this maximum range will be called "Egg Laying Radius (ELR)". In an optimization problem with upper limit of $\operatorname{var}_{h i}$ and lower limit of $\operatorname{var}_{\text {low }}$ for variables, each cuckoo has an egg laying radius (ELR) which is proportional to the total number of eggs, number of current cuckoo's eggs and also variable limits of $\operatorname{var}_{h i}$ and $\operatorname{var}_{l o w}$. So ELR is defined as:

$$
E L R=\alpha \times \frac{\text { numberof currentcuckoo's eggs }}{\text { totalnumberof eggs }} \times\left(\operatorname{var}_{h i}-\operatorname{var}_{l o w}\right)
$$

Where $\alpha$ is an integer, supposed to handle the maximum value of ELR.

\subsection{Cuckoos' style for egg laying}

Each cuckoo starts laying eggs randomly in some other host birds' nests within her ELR. Figure 4 gives a clear view of this concept.

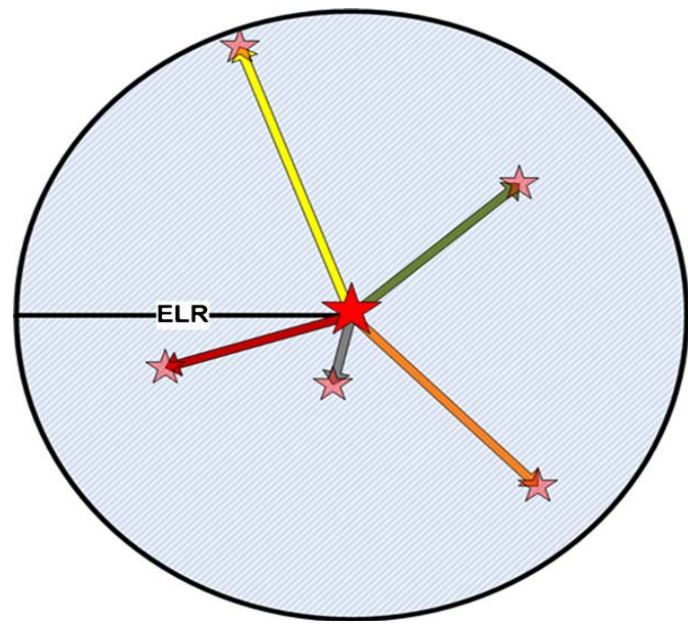

Figure 4. Random egg laying in ELR, central red star is the initial habitat of the cuckoo with 5 eggs; pink stars are the eggs' new nest.

After all cuckoos' eggs are laid in host birds' nests, some of them that are less similar to host birds' own eggs, are detected by host birds and though are thrown out of the nest. So after egg laying process, p\% of all eggs (usually 10\%), with less profit values, will be killed. These eggs have no chance to grow. Rest of the eggs grow in host nests, hatch and are fed by host birds. Another interesting point about laid cuckoo eggs is that only one egg in a nest has the chance to grow. This is because when cuckoo egg hatches and the chicks come out, she 
throws the host bird's own eggs out of the nest. In case that host bird's eggs hatch earlier and cuckoo egg hatches later, cuckoo's chick eats most of the food host bird brings to the nest (because of her 3 times bigger body, she pushes other chicks and eats more). After couple of days the host bird's own chicks die from hunger and only cuckoo chick remains in the nest.

\subsection{Immigration of cuckoos}

When young cuckoos grow and become mature, they live in their own area and society for some time. But when the time for egg laying approaches they immigrate to new and better habitats with more similarity of eggs to host birds and also with more food for new youngsters. After the cuckoo groups are formed in different areas, the society with best profit value is selected as the goal point for other cuckoos to immigrate.

\subsection{Convergence}

After some iterations, all the cuckoo population moves to one best habitat with maximum similarity of eggs to the host birds and also with the maximum food resources. This habitat will produce the maximum profit ever. There will be least egg losses in this best habitat. Convergence of more than $95 \%$ of all cuckoos to the same habitat puts an end to Cuckoo Optimization Algorithm (COA).

\section{Apply COA Algorithm in order to Optimal Coordination of Relays}

Relay coordination problems, is an optimization problem with constraints and many local optimum points. In the usual methods, such as linear programming, non-linear programming and integer programming, since optimization start with initial point, the final answer depends heavily on that point and may lead to a local optimization. However COA starts the search from a population of initial points, therefore in the local optimum points the possibility of stopping this algorithm is very low. COA algorithm, problem's variables are encoded into strings, so each string represents an answer to the problem of coordination.

\subsection{Encoded variables}

In the relays coordination problem, the decision variables are the TMS and Iset variables for each relay. Therefore, in the COA method a habitat is defined in the form of a string which contains both TMS and $\mathrm{I}_{\text {set }}$ parameters as discrete variables. Figure 5 shows structure of the habitat when the network consists of $n$ overcurrent relays.

\begin{tabular}{|l|l|l|l|l|l|l|}
\hline $\mathrm{I}_{\text {set1 }}$ & TMS $_{1}$ & $\mathrm{I}_{\text {set2 }}$ & TMS $_{2}$ & $\cdots$ & $\mathrm{I}_{\text {setn }}$ & TMS $_{\mathrm{n}}$ \\
\hline
\end{tabular}

Figure 5. Structure of the habitat in the COA method.

\subsection{New method}

In the proposed coordination method for the overcurrent and distance relays, the objective function optimization problem is formulated as [18]:

$$
\begin{aligned}
O . F= & \alpha_{1} \times \sum_{i=1}^{N}\left(t_{i}\right)^{2}+\beta_{2} \times \sum_{k_{1}=1}^{P_{1}}\left(\Delta t_{m b}\left|K_{1}\right|^{-}\left|\Delta t_{m b}\right| K_{1}||\right)^{2} \\
& +\beta_{3} \times \sum_{k_{2}=1}^{P_{2}}\left(\Delta t_{m b D I S O C}\left|K_{2}\right|^{-}\left|\Delta t_{m b D I S O C}\right| K_{2}||^{2}\right.
\end{aligned}
$$

Where $\alpha_{1}, \beta_{2}, \beta_{3}$ are the weighting factors, $i$ is the number of overcurrent relays that changes from 1 to $\mathrm{N}, k_{1}$ is the number of main and backup overcurrent relays that changes from 1 to $P_{1}, \mathrm{k} 2$ is the number of main distance and backup overcurrent relays changing from 1 to $P_{2}$, $\Delta t_{m b\left|K_{1}\right|}$ is the discrimination time between the main and backup overcurrent relays. $\Delta t_{m b D I S O C\left|K_{2}\right|}$ is the discrimination time between the main distance and backup overcurrent relays which is obtained from the equation (12): 


$$
{ }^{\Delta t}{ }_{\text {mbDISOC }}\left|\mathrm{K}_{2}\right|^{=}{ }^{\mathrm{t}} \text { boc }\left|\mathrm{k}_{2}\right|^{-\mathrm{t}}{ }_{\mathrm{mDIS}}\left|\mathrm{k}_{2}\right|^{-\mathrm{CTI}}
$$

Where $t_{b o c\left|k_{2}\right|}$ is the operating time of backup overcurrent relay for the fault at the end of the first zone of main distance relay (critical fault locations), $t_{m D I S \mid k_{2}} \mid$ is the operating time of the second zone of main distance relay and CTI is the coordination time interval that is equal to $0.3(\mathrm{sec})$.

Two first terms of (11) are the same as the OF in [10]. The third term is added to OF for the Coordination of overcurrent and distance relays. To describe the role of this new term, assume that $\Delta t_{m b D I S O C\left|K_{2}\right|}$ is positive (fully coordinated), then the relative term in (11) becomes zero and OF also has a small value. However if $\Delta t_{m b D I S O C}\left|K_{2}\right|$ is negative (miscoordination) the mentioned term will be equal to $2 \beta_{3} \times \Delta \mathrm{t}_{\text {mbDISOC }\left|\mathrm{k}_{2}\right|}$ and obviously for positive values of $\beta_{3}$ the new term will have large values, that COA algorithm removes it from the selection then, based on the concept of the evaluation and selection, those values that have more optimal OF values (less value) in the habitat, are granted more opportunities to be selected for the next iteration. By solving COA, $\mathrm{I}_{\text {set }}$ and TMS for all relays will be determined in a manner that the relays have a least operation time and will satisfy all constraints.

\section{Simulation Results and Discussion}

The proposed method is applied to an 8-bus, 9-branch network shown in Figure. 6. At bus 4 , there is a link to another network which is modeled by a short circuit capacity of 400 MVA. The parameters used in the network is provided in reference [27]. The transmission network consists of 14 relays which their location are indicated in Figure. 6 . The TMS values can range continuously from 0.1 to 1.1 , while seven available discrete pickup tap settings $(0.5$, $0.6,0.8,1.0,1.5,2.0$ and 2.5) are considered. The generation size and population size is directly related to the habitat length; for longer lengths, more habitats should be produced. The generation size and the population size are considered to be 300 and 100, respectively.

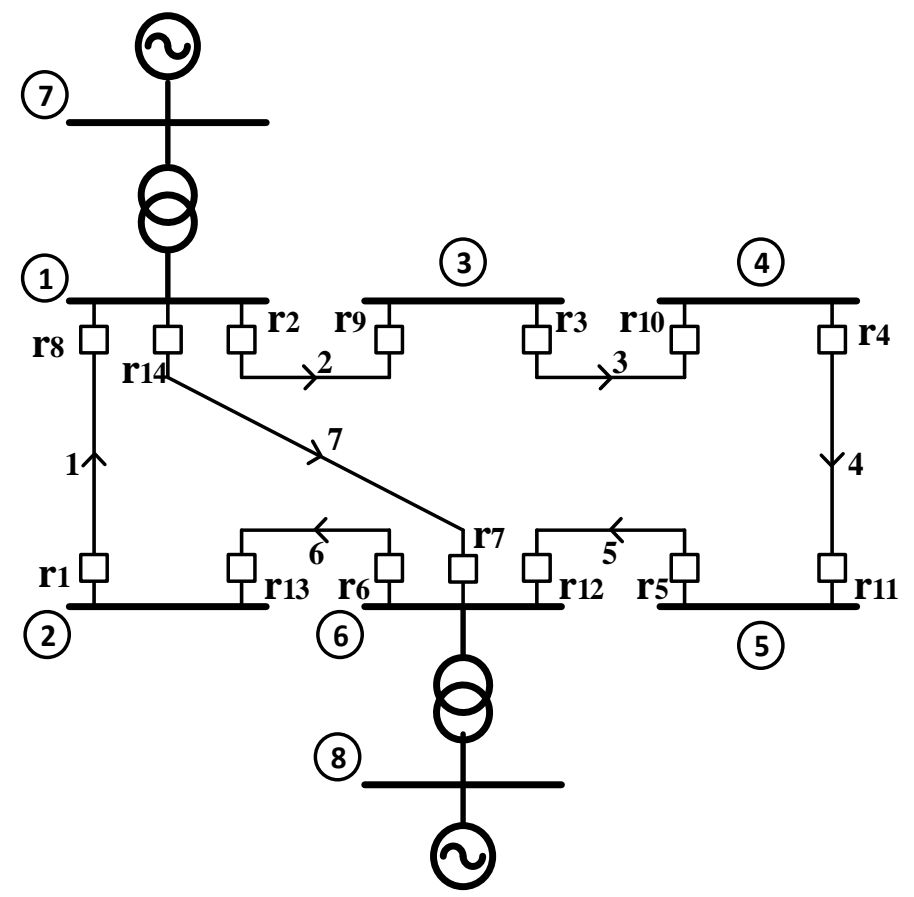

Figure 6. 8-busbars test system 
This paper is solve the optimal coordination distance and overcurrent relays to verify the effectiveness of the proposed Cuckoo Optimization Algorithm (COA). For comparison purposes Genetic Algorithm (GA), Particle Swarm Optimization (PSO), Differential Evolutionary (DE) and Cuckoo Optimization Algorithm (COA) were used in the system. Table 1 shows the primary/backup (P/B) relay pairs and corresponding fault currents passing through them for fault in front of the main relay and fault on bus away the main relay in the studied system. This matrix contains 20 rows and two columns. The first column is the number of the main relay and the second column is the number of backup relay. Then, for a short circuit in front of the main relay the fault currents passing through the primary/backup (P/B) relay pairs, is calculated and is stored in the IP and IB matrix respectively, as shown in Table 1. Obviously, when the system topology is changed the presented data in Table 1 should be updated.

Table 1. P/B Relay pairs and the fault currents in the main network topology

\begin{tabular}{|c|c|c|c|}
\hline \multicolumn{2}{|c|}{ P/B pair } & \multicolumn{2}{c|}{ Near-End Fault Currents(A) } \\
\hline $\begin{array}{c}\text { primary } \\
\text { relays }\end{array}$ & $\begin{array}{c}\text { backup } \\
\text { relays }\end{array}$ & IP & IB \\
\hline 2 & 1 & 5910 & 993 \\
14 & 1 & 5190 & 993 \\
3 & 2 & 3550 & 3550 \\
4 & 3 & 3780 & 2240 \\
5 & 4 & 2400 & 2400 \\
6 & 5 & 6100 & 1200 \\
7 & 5 & 5210 & 1200 \\
1 & 6 & 3230 & 3230 \\
2 & 7 & 5910 & 1880 \\
8 & 7 & 6080 & 1880 \\
13 & 8 & 2980 & 2980 \\
8 & 9 & 6080 & 1160 \\
14 & 9 & 5190 & 1160 \\
9 & 10 & 2480 & 2480 \\
10 & 11 & 3880 & 2340 \\
11 & 12 & 3700 & 3700 \\
7 & 13 & 5210 & 985 \\
12 & 13 & 5890 & 985 \\
6 & 14 & 6100 & 1870 \\
12 & 14 & 5890 & 1870 \\
\hline
\end{tabular}

Initially, the setting parameters for the case that only the overcurrent relays are used in the network have been identified. The setting current of relays is obtained by using the power flow. Then $\mathrm{I}_{\text {set }}$ and TMS overcurrent relays have been obtained using COA, DE-GA, GA, PSO and DE algorithms, as shown in the table 2. Also, the ratios of the current transformers (CTs) are indicated in Table 2. It is obvious that the Cuckoo Optimization Algorithm (COA) have the operation time and the fitness value less compared to the other algorithms. In other words, COA gave the best results when compare with three well known algorithms DE, GA and PSO.

$\mathrm{I}_{\text {set }}$ and TMS are the results of the optimal coordination distance and overcurrent relays, which have been obtained using COA, DE-GA, GA, PSO and DE algorithms, as shown in the table 3. $\mathrm{t}_{\mathrm{z} 2}$ is selected based on reference data [11] which is calculated the second zone of distance relays. The performance of a distance relay near its zone boundaries is not very predictable because of various types of errors. In this article, from multiple zones of protection are used to cover the entire line dependably and securely. Zone 1 relay operates instantaneously (no intentional delay - i.e. in about one to two cycles) while a fault in Zone 2 causes the relay to operate with an added delay (generally of the order of 20 to 30 cycles). In this fashion, the entire line is protected even where the zone boundary is not very precisely determined. In addition to these two zones, often a third zone (with an additional time delay about one second) is provided at each end in order to provide remote backup for the protection of the adjacent circuits. It should be noted that often, due to system load, it is not possible to obtain a secure Zone 3 setting on high voltage networks. It is obvious that COA have operation time and the fitness value less compared to the other algorithms.

TELKOMNIKA Vol. 16, No. 3, December 2015: $389-400$ 
Table 2. Overcurrent relay settings regardless of distance relays

\begin{tabular}{|c|c|c|c|c|c|c|c|c|c|c|c|}
\hline \multirow[t]{2}{*}{$\begin{array}{l}\text { Rrlay } \\
\text { No. }\end{array}$} & \multirow[t]{2}{*}{$\begin{array}{c}\text { CT } \\
\text { Ratio }\end{array}$} & \multicolumn{2}{|c|}{$\begin{array}{c}\text { The results of } \\
\text { the program } \\
\text { GA [2] } \\
\text { Fitness }=7.63\end{array}$} & \multicolumn{2}{|c|}{$\begin{array}{c}\text { The results of } \\
\text { the program } \\
\text { PSO [13] } \\
\text { Fitness }=6.8476\end{array}$} & \multicolumn{2}{|c|}{$\begin{array}{c}\text { The results of } \\
\text { the program } \\
\text { DE [9] } \\
\text { Fitness }=6.29\end{array}$} & \multicolumn{2}{|c|}{$\begin{array}{l}\text { The results of } \\
\text { the program } \\
\text { DE-GA } \\
\text { Fitness }=4.15\end{array}$} & \multicolumn{2}{|c|}{$\begin{array}{c}\text { The results of } \\
\text { the program } \\
\text { COA } \\
\text { Fitness }=4.041\end{array}$} \\
\hline & & TMS & Iset & TMS & Iset & TMS & Iset & TMS & Iset & TMS & $I_{\text {set }}$ \\
\hline 1 & 240 & 0.25 & 000 & 0. & 2.5000 & 0.1000 & 1. & 7 & 2.0000 & 000 & .5000 \\
\hline 2 & 240 & 0.19 & 1.5000 & 0.1 & 2.0000 & 0.12 & 1.00 & 0.1 & 1.5000 & 0.1000 & .5000 \\
\hline 3 & 160 & 0.21 & 0.6000 & 0.1267 & 1.5000 & 0.1561 & 2.5000 & 0.1520 & 0.5000 & 0.1045 & 2.5000 \\
\hline 4 & 240 & 0.17 & 0.6000 & 0.1421 & 1.5000 & 0.1271 & 2.0000 & 0.1310 & 0.5000 & 1075 & 0.8000 \\
\hline 5 & 240 & 0.10 & 0.5000 & 0.10 & 0.8000 & 0.10 & 0.50 & 0.10 & 0.6000 & 0.1010 & 0.6000 \\
\hline 6 & 240 & 0.20 & 0.8000 & 0.1855 & 0.5000 & 0.2527 & 0.8000 & 0.1904 & 2.0000 & 0.8365 & 2.0000 \\
\hline 7 & 160 & 0.20 & 0.6000 & 0.1542 & 2.0000 & 0.2297 & 1.0000 & 0.1998 & 1.0000 & 0.7497 & 2.5000 \\
\hline 8 & 240 & 0.17 & 1.0000 & & 2.5000 & 0.10 & & 0.22 & 0.6 & 08 & 2.5000 \\
\hline 9 & 160 & 0.09 & 0.6000 & 0.1000 & 0.5000 & 0.1000 & 0.5000 & 0.1000 & 0.5000 & 0.1058 & 0.5000 \\
\hline 10 & 240 & 0.16 & 0.8000 & 0.1001 & 2.0000 & 0.1944 & 0.6000 & 0.1000 & 0.8000 & 0.1019 & 1.5000 \\
\hline 11 & 240 & 0.20 & 0.6000 & 0.1821 & 2.5000 & 0.1123 & 2.0000 & 0.1771 & 0.8000 & 0.1000 & 0.8000 \\
\hline 12 & 240 & 0.26 & 0.8000 & 0.1242 & 1.0000 & 0.15 & 0.6000 & 0.1511 & 1.0000 & 0.1011 & 2.0000 \\
\hline 13 & 240 & 0.18 & 0.6000 & 0.10 & 1.5000 & 0.12 & 1.5000 & 0.1214 & 1.0000 & 0.1007 & 1.0000 \\
\hline 14 & 160 & 0.16 & 0.8000 & 0.1625 & 1.5000 & 0.1728 & 2.5000 & 0.1662 & 2.0000 & 0.7484 & 2.5000 \\
\hline
\end{tabular}

Table 3. The results of the optimal coordination of overcurrent and distance relays

\begin{tabular}{|c|c|c|c|c|c|c|c|c|c|c|}
\hline \multirow[t]{2}{*}{$\begin{array}{c}\text { Relay } \\
\text { No. }\end{array}$} & \multicolumn{2}{|c|}{$\begin{array}{c}\text { The results of the } \\
\text { program GA } \\
\text { Fitness }=49.16\end{array}$} & \multicolumn{2}{|c|}{$\begin{array}{c}\text { The results of the } \\
\text { program PSO } \\
\text { Fitness }=67.41\end{array}$} & \multicolumn{2}{|c|}{$\begin{array}{c}\text { The results of the } \\
\text { program DE } \\
\text { Fitness }=31.95\end{array}$} & \multicolumn{2}{|c|}{$\begin{array}{c}\text { The results of the } \\
\text { program DE-GA } \\
\text { Fitness }=19.71\end{array}$} & \multicolumn{2}{|c|}{$\begin{array}{c}\text { The results of the } \\
\text { program COA } \\
\text { Fitness }=18.27\end{array}$} \\
\hline & TMS & $I_{\text {set }}$ & TMS & $I_{\text {set }}$ & TMS & $\mathrm{I}_{\text {set }}$ & TMS & $I_{\text {set }}$ & TMS & $\mathrm{I}_{\mathrm{S}}$ \\
\hline 1 & 0.1257 & 0.5000 & 0.5303 & 0.8000 & 0.3254 & 0.5000 & 0.1471 & 0.6000 & 0.1245 & 0.5000 \\
\hline 2 & 0.6718 & 0.5000 & 0.3158 & 2.5000 & 0.6901 & 0.5000 & 0.1537 & 2.5000 & 0.1548 & 2.5000 \\
\hline 3 & 0.5492 & 0.6000 & 0.4099 & 2.0000 & 0.4214 & 0.5000 & 0.1723 & 1.5000 & 0.1546 & 2.0000 \\
\hline 4 & 0.5672 & 2.0000 & 0.5942 & 0.6000 & 0.2123 & 1.5000 & 0.1541 & 0.5000 & 0.1236 & 0.8000 \\
\hline 5 & 0.1000 & 0.5000 & 0.1002 & 0.6000 & 0.1005 & 0.5000 & 0.1000 & 1.0000 & 0.1002 & 0.6000 \\
\hline 6 & 0.1928 & 0.5000 & 0.2596 & 1.5000 & 0.5566 & 0.6000 & 0.2396 & 0.8000 & 0.2128 & 2.0000 \\
\hline 7 & 0.7362 & 2.5000 & 0.5994 & 1.0000 & 0.8096 & 2.5000 & 0.2455 & 2.5000 & 0.2518 & 2.0000 \\
\hline 8 & 0.9238 & 0.6000 & 0.7668 & 0.5000 & 0.5237 & 1.5000 & 0.2119 & 0.5000 & 0.1945 & 1.5000 \\
\hline 9 & 0.1005 & 0.5000 & 0.1001 & 0.5000 & 0.1001 & 1.0000 & 0.1000 & 2.0000 & 0.1000 & 0.8000 \\
\hline 10 & 0.5289 & 2.0000 & 0.5354 & 0.5000 & 0.6531 & 0.5000 & 0.1006 & 1.5000 & 0.1056 & 0.5000 \\
\hline 11 & 0.6345 & 0.8000 & 0.8850 & 0.6000 & 0.5007 & 0.5000 & 0.1786 & 0.8000 & 0.1549 & 0.6000 \\
\hline 12 & 0.7155 & 0.5000 & 0.7919 & 0.8000 & 1.0000 & 0.5000 & 0.1948 & 0.6000 & 0.2015 & 2.0000 \\
\hline 13 & 0.2886 & 0.6000 & 0.4904 & 0.8000 & 0.3005 & 2.5000 & 0.1465 & 0.5000 & 0.1517 & 2.5000 \\
\hline 14 & 0.4437 & 1.0000 & 0.7844 & 1.0000 & 0.4809 & 2.0000 & 0.2398 & 1.0000 & 0.5482 & 0.5000 \\
\hline
\end{tabular}

In order to assess the validity of the obtained settings, relays performance was evaluated caused by a short circuit fault per $40 \%$ of line the front of relay 7 . In the ring networks, like the network figure.6, the relays setting is complex in front of generator bus, like relays 5 and 9 which are backup relays for 6,7 and 8, 14 respectively. When in the front of lines of relays 6 , $7,8,14$ a short circuit occurs, if the backup relays 5 and 9 are not set correctly, it is possible fault current passing through them be less than the current set, and thus does not operate as a backup of the primary relays. According to the tables 2 and 3, in all the cases studied, relays 5 and 9 are set at the lowest value.

Figure. 7 illustrated comparative convergence performance of objective function. It is obvious that the Cuckoo Optimization Algorithm (COA) gave the accurate and convergence with faster computational time compared to other method. This novel evolutionary algorithm, is suitable for continuous nonlinear optimization problems. Therefore, application of the proposed algorithm to some benchmark functions and a real problem has proven its capability to deal with difficult optimization problems. As a result, COA algorithm have operation time and the fitness value less compared to other algorithms.

Table 4 shows that the operation time differences of all overcurrent relays is more than operation time zone 2 distance relays which indicates the correct coordination between distance and overcurrent relays. All $\Delta \mathrm{t}$ values are positive and most of them are small that means the setting of overcurrent relays is very accurate and there is no miscoordination. 


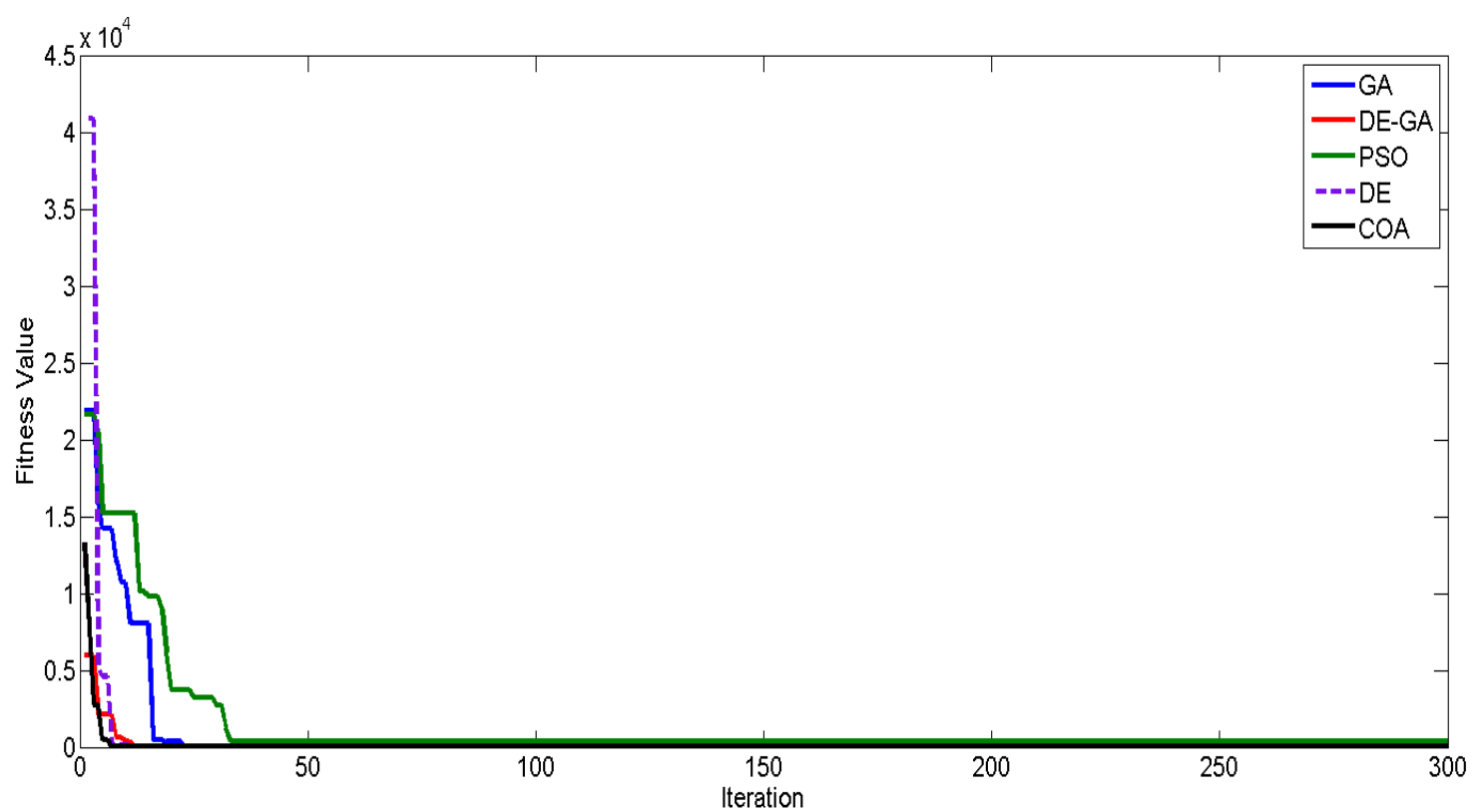

Figure 7. Comparison of objective function for 8-busbars test system

Table 4. The operating time overcurrent relays from performance of zone 2 distance relays

\begin{tabular}{|c|c|c|}
\hline primary relays & backup relays & $\Delta t$ \\
\hline 2 & 1 & 0.6433 \\
14 & 1 & 0.9101 \\
3 & 2 & 0.1445 \\
4 & 3 & 0.0613 \\
5 & 4 & 0.0162 \\
6 & 5 & 0.3666 \\
7 & 5 & 0.9018 \\
1 & 6 & 0.1991 \\
2 & 7 & 0.7990 \\
8 & 7 & 0.3606 \\
13 & 8 & 0.5632 \\
8 & 9 & 0.4041 \\
14 & 9 & 0.1092 \\
9 & 10 & 0.9236 \\
10 & 11 & 0.0033 \\
11 & 12 & 0.0406 \\
7 & 13 & 0.5249 \\
12 & 13 & 0.6401 \\
6 & 14 & 0.1655 \\
12 & 14 & 0.8158 \\
\hline
\end{tabular}

\section{Conclusion}

Protection of power distribution, sub-transmission and transmission networks is a crucial issue in determining the stability and the reliability of a power system. To have better protection it is common to combine different types of relays, which combination of overcurrent and distance relay is a well-known protection scheme in transmission lines. Applying optimizing algorithms to the issues existing in power networks improve the security level of the networks. The execution time of the algorithm and the accuracy of the results extracted from the algorithm are two determining parameters in choosing the optimization algorithm in protective functions. In this article, a method based on Cuckoo Optimization Algorithm (COA) has been applied to the optimal coordination of overcurrent and distance relays problem. The key features of COA are the faster convergence rate and reduce computational complexity. Application of the proposed algorithm to some benchmark functions and a real problem has proven its capability to deal with difficult optimization problems. Results show the proposed method has significantly reduced the 
execution time of the algorithm while improving the accuracy of the output results in comparison with the other nature-inspired algorithms such as PSO and GA.

\section{References}

[1] Jianbin X, Yanqin Z, Lijing Q, Bo L. Research on Relay-Assisted Cellular System Coordination Mechanism Based on Energy-Efficient. TELKOMNIKA Indonesian Journal of Electrical Engineering. 2013; 11(9): 5502-5508.

[2] Ezzeddine M, Kaczmarek R. A novel method for optimal coordination of directional overcurrent relays considering their available discrete settings and several operation characteristics. Electric Power Systems Research. 2011; 81(7): 1475-1481.

[3] Singh M, Panigrahi BK, Abhyankar AR. Optimal coordination of directional over-current relays using Teaching Learning-Based Optimization (TLBO) algorithm. Electrical Power and Energy Systems. 2013; 50: 33-41.

[4] Kheirollahi R, Namdari F. Optimal Coordination of Overcurrent Relays Based on Modified Bat Optimization Algorithm. International Electrical Engineering Journal (IEEJ). 2014; 5(2): 1273-1279.

[5] Abdelaziz AY, Talaat HEA, Nosseir AI, Hajjar AA. An adaptive protection scheme for optimal coordination of overcurrent relays. Electric Power Systems Research. 2002; 61(1): 1-9.

[6] Chaudhari VS, Upadhyay VJ. Coordination of overcurrent relay in interconnected power system protection. In National Conference on Recent Trends in Engineering \& Technology. 2011.

[7] Barzegari M, Bathaee SMT, Alizadeh M. Optimal coordination of directional overcurrent relays using harmony search algorithm. in Environment and Electrical Engineering(EEEIC), 9th International Conference on. 2010: 321-324.

[8] Zellagui M, Chaghi A. Impact of RDG Location on IDMT Overcurrent Relay Operation and Coordination in MV Distribution System. TELKOMNIKA Indonesian Journal of Electrical Engineering. 2014; 12(11): 7585-7594.

[9] Chelliah TR, Thangaraj R, Allamsetty S, Pant M. Coordination of directional overcurrent relays using opposition based chaotic differential evolution algorithm. International Journal of Electrical Power \& Energy Systems. 2014; 55: 341-350.

[10] Bedekar PP, Bhide SR. Optimum coordination of overcurrent relay timing using continuous genetic algorithm. Expert Systems with Applications. 2011; 38(9): 11286-11292.

[11] Uthitsunthorn D, Kulworawanichpong T. Optimal overcurrent relay coordination using genetic algorithms. Advances in Energy Engineering (ICAEE), International Conference on. 2010: 162-165.

[12] Razavi F, Askarian HA, Al-Dabbagh M, Mohammadi R, Torkaman H. A new comprehensive genetic algorithm method for optimal overcurrent relays coordination. Electric Power Systems Research. 2008; 78(4): 713-720.

[13] Mansour MM, Mekhamer SF. A Modified particle swarm optimizer for the coordination of directional overcurrent relays. IEEE Transactions on Power Delivery. 2007; 20(3): 1400-1410.

[14] Bansal JC, Deep K. Optimization of directional overcurrent relay times by particle swarm optimization. In Swarm Intelligence Symposium SIS, IEEE. 2008: 1-7.

[15] Chabanloo RM, Abyaneh HA, Kamangar SSH, Razavi F. A new genetic algorithm method for optimal coordination of $\mathrm{O} / \mathrm{C}$ and distance relays considering various characteristics for $\mathrm{O} / \mathrm{C}$ relays. presented PECON Conf., Johor Bahru, Malaysia. 2008: 569-573.

[16] Sidhu TS, Baltazar DS, Palomino RM, Sachdev MS. A New Approach for Calculating Zone-2 Setting of Distance Relays and Its Use in an Adaptive Protection System. IEEE Transactions on Power Delivery. 2004; 19(1): 70-77.

[17] Perez LG, Urdaneta AJ. Optimal Computation of Distance Relays Second Zone Timing in a Mixed Protection Scheme with Directional Relays. IEEE Transaction on Power Delivery. 2001; 16(3): 385-388.

[18] Chabanloo RM, Abyaneh HA, Kamangar SSH, Razavi F. Optimal combined overcurrent and distance relays coordination incorporating intelligent overcurrent relays characteristic selection. IEEE Transactions on Power Delivery. 2011; 26(3): 1381-1391.

[19] Uthitsunthorn D, Pao-La-Or P, Kulworawanichpong T. Optimal overcurrent relay coordination using artificial bees colony algorithm. In Electrical Engineering/Electronics, Computer, Telecommunications and Information Technology (ECTI-CON), 8th International Conference on. 2011: 901-904.

[20] Phadke AG, Thorp JS. COMPUTER RELAYING FOR POWER SYSTEMS. John Wiley \& Sons Ltd. 2009.

[21] Thangaraj R, Pant M, Deep K. Optimal coordination of over-current relays using modified differential evolution algorithms. Engineering Applications of Artificial Intelligence. 2010; 23(5): 820-829.

[22] llango R. Impact Analysis of midpoint Connected STATCOM on Distance Relay Performance. TELKOMNIKA Indonesian Journal of Electrical Engineering. 2015; 13(2): 257-263.

[23] Singh DK, Gupta S. Optimal coordination of directional overcurrent relays: A genetic algorithm approach. In Electrical, Electronics and Computer Science (SCEECS), 2012 IEEE Students Conference on. 2012: 1-4.

[24] Moravej Z, Jazaeri M, Gholamzadeh M. Optimal coordination of distance and overcurrent relays in series compensated systems based on MAPSO. Energy Conversion and Management. 2012; 56: 140-151.

[25] Rajabioun R. Cuckoo optimization algorithm. Applied soft computing. 2011; 11(8): 5508-5518. 
[26] Karegar HK, Abyaneh HA, Ohis V, Meshkin M. Pre-processing of the optimal coordination of overcurrent relays. Electric Power Systems Research. 2005; 75(2): 134-141.

[27] Mohammadi R, Abyaneh HA, Razavi F, Al-Dabbagh M, Sadeghi S. Optimal relays coordination efficient method in interconnected power systems. Journal of Electrical Engineering. 2010; 61(2): 7583.

TELKOMNIKA Vol. 16, No. 3, December 2015: $389-400$ 